\title{
Bilateral pheochromocytoma after kidney transplantation in neurofibromatosis type 1
}

\author{
Valeria de Miguel'1, Andrea Paissan'1, Patricio García Marchiñena², Alberto Jurado², \\ Mariana Isola ${ }^{3}$, José Alfie ${ }^{4}$ and Patricia Fainstein-Day ${ }^{1}$
}

Departments of ${ }^{1}$ Endocrinology, Metabolism and Nuclear Medicine, 2Urology, ${ }^{3 P a t h o l o g y}$, and 4 Hypertension Unit of Hospital Italiano de Buenos Aires, Buenos Aires, Argentina
Correspondence should be addressed to $\mathrm{V}$ de Miguel

Email

valeria.demiguel@

hospitalitaliano.org.ar

\section{Summary}

We present the case of a 25-year-old male with a history of neurofibromatosis type 1 and bilateral pheochromocytoma 4 years after kidney transplantation that was successfully treated with simultaneous bilateral posterior retroperitoneoscopic adrenalectomy.

\section{Learning points:}

- Hypertensive patients with NF1 should always be screened for pheochromocytoma.

- Pheochromocytoma is rarely associated with transplantation, but it must be ruled out in patients with genetic susceptibility.

- Posterior retroperitoneoscopic adrenalectomy (PRA) allows more direct access to the adrenal glands, especially in patients with previous abdominal surgeries.

\section{Background}

The prevalence of hypertension is very high in kidney transplant recipients and secondary causes should be excluded.

Neurofibrormatosis type 1 (NF1) is a common genetic condition with a prevalence of $1 / 3000$. Pheochromocytomas (PHEOs) occur in about $0.1-5.7 \%$ of patients with NF1 mutations (1).

We describe the case of a NF1 patient with bilateral pheochromocytoma (PHEO) diagnosed after kidney transplantation who was successfully treated with simultaneous bilateral PRA.

\section{Case presentation}

A 25-year-old man with a history of NF1 and end-stage disease due to congenital renal dysplasia underwent a second kidney transplantation 7 years ago. He was on immunosuppressive therapy with methylprednisolone, mycophenolate and tacrolimus.
Four years after transplantation, the patient presented sustained hypertension. His blood pressure (BP) was around 200/100 $\mathrm{mmHg}$ despite maximum doses of five antihypertensive drugs including diuretics. He reported episodes of sweating, headaches and palpitations.

He was admitted to our hospital for resistant hypertension and renal failure. Clinical examination revealed hypertension (BP: $210 / 110 \mathrm{mmHg}$ ), tachycardia (110BPM), café-au-lait spots, skin neurofibromas and genu varum. Allograft nephropathy and renovascular disease were excluded.

BP was controlled with doxazosin, nebivolol and amlodipine.

\section{Investigation}

Computed tomography (CT) scans showed enlargement of the adrenal glands (Fig. 1A, B and C: Abdomen CT (c) 2019 The authors
https://edm.bioscientifica.com/
Published by Bioscientifica Ltd 

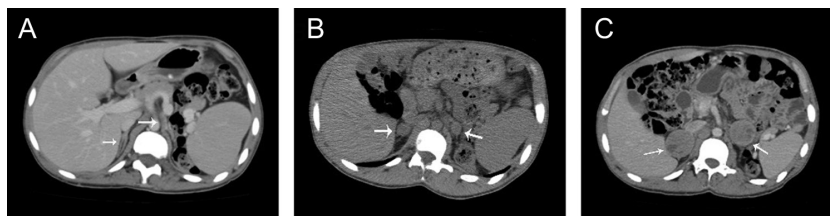

Figure 1

Abdomen CT scans follow-up. (A) Absence of native kidneys and normal adrenal glands (2010). (B) Abdomen CT scan showed enlargement of the adrenal glands $18 \mathrm{~mm}$ right and $16 \mathrm{~mm}$ left (2014). (C) Abdomen CT scan showed enlargement of the adrenal glands $43 \mathrm{~mm}$ right and $45 \mathrm{~mm}$ left (2016). Arrows indicate adrenal gland.

scans follow-up). The 24-h urinary metanephrines were highly elevated (Table 1 ).

\section{Treatment}

The patient underwent a successful bilateral (PRA) with two separate surgical teams that simultaneously performed the resection of the right and left tumor with no need to reposition the patient who remained in ventral decubitus. The operating time was $171 \mathrm{~min}$. During surgery, there was a rise in $\mathrm{BP}$ that was controlled with intravenous phentolamine (total dose $31 \mathrm{mg}$ ) and labetalol. Pathology report confirmed PHEO diagnosis (Fig. 2A and B).

He is on prednisone and fludrocortisone therapy.

\section{Outcome and follow-up}

Two years after surgery, he is normotensive with no antihypertensive treatment. Renal function and urinary metanephrines are within the normal range.

\section{Discussion}

\section{Pheochromocytoma in NF1}

Pheochromocytomas are rare neuroendocrine tumors arising from chromaffin cells of the adrenal medulla that predispose to cardiovascular morbidity and mortality (2).

The incidence of PHEO in NF1 patients is relatively low compared to other hereditary syndromes. Most NF1related-PHEO's are unilateral (84\%), 10\% are bilateral and a small percentage $(6 \%)$ are extra adrenal or paragangliomas

Table 1 24-h urinary metanephrines (urinary volume $10 \mathrm{~L}$ ).

\begin{tabular}{|c|c|}
\hline Biochemistry & Result \\
\hline Creatinine (0.7 a 1.1 mg/dL) & $1.6 \mathrm{mg} / \mathrm{dL}$ \\
\hline $\begin{array}{l}\text { Urinary total metanephrines } \\
(150-1200 \mu g / 24 \mathrm{~h})\end{array}$ & $20.055 \mu g / 24 h$ \\
\hline Urinary metanephrines (50-400 g/24 h) & $5380 \mu g / 24 h$ \\
\hline Urinary normetanephrines (100-800 g/24 h) & $14675 \mu g / 24 \mathrm{~h}$ \\
\hline
\end{tabular}
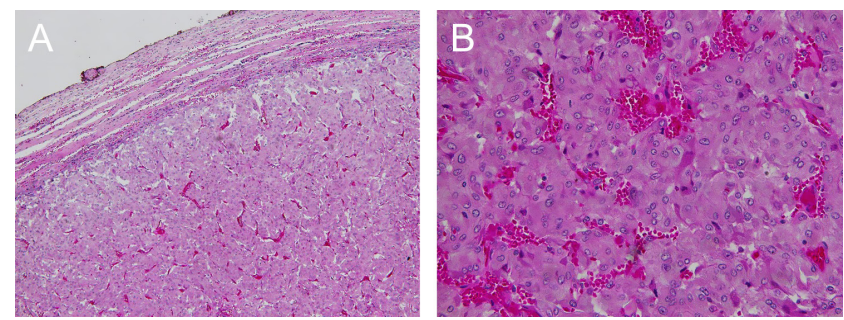

\section{Figure 2}

Microscopy. (A and B) Tumor proliferation constituted by fused cells in nests.

(PGL) $(1,2)$. Mayo Clinic reported in a cohort study from 1959 to 2015 that the prevalence of PHEO/PGL in patients with NF1 was $2.9 \%$ and the median age at the time of diagnosis was 41 years. Bilateral PHEO was identified in $17 \%$ of patients and metastatic or recurrent disease occurred in 7.3\%. Mayo Clinic recommends biochemical test detection for PHEO/PGL every 3 years starting from 10 to 14 years, prior to elective surgical procedure and conception, and lifelong annual biochemical surveillance in patients with prior diagnosis of PHEO/PGL (3).

\section{Renal transplantation and neoplasia}

Neurofibromatosis (NF1) gene is a tumor suppressor gene that encodes for the protein neurofibromin. This protein downregulates the RAS signaling pathway. RAS is an important oncogene in human cancer and activates a number of signaling pathways such as MAP kinase and mTOR leading to proliferation and survival of NF1deficient cells of nerve tumors and PHEO/PGL (1).

Cancer is more frequent after solid organ transplantation including the kidney. Younger patients appeared to be more affected and immunodeficiency-related malignancies are the more frequently seen (4). Only five patients with PHEO/ PGL diagnosis after solid organ transplantation have been reported. None of them harbored NF1 or other hereditary cancer syndrome $(5,6,7,8,9)$. Immunosuppression does not seem to play a significant role in these types of tumors. Compared to other NF1 reports, our patient was younger and had bilateral disease $(1,3)$.

\section{Simultaneous PRA}

Although laparoscopic adrenalectomy is the preferred therapy for pheochromocytoma, experience with simultaneous laparoscopic bilateral adrenalectomy is limited (10). The large work space and easiness to find anatomical landmarks made the transperitoneal approach the one used most often in our midst. Since the adrenal glands are two small organs located deep 
in the abdomen surrounded by retroperitoneal fat, therefore having a right exposure can be difficult. In this context, retroperitoneoscopic surgery is an interesting option that allows a more direct access to the adrenal gland, especially in cases such as our patient with significant history of abdominal surgeries and bilateral adrenal tumors. Not repositioning the patient, avoiding the abdominal cavity, addressing a simultaneous and synchronous adrenalectomy and offering a minimally invasive approach were perhaps the main advantages. Nevertheless, the PRA technique has certain drawbacks, such as instrument clashing and limitations of working in a small space.

It is very important to perform a strict intraoperative monitoring of BP, since anesthetic induction, the creation of the pneumoretroperitoneum and the manipulation of the tumor produce great release of catecholamines. In our patient, despite simultaneous resection of both tumors, adequate control of BP was maintained with high doses of intravenous phentolamine and labetalol.

\section{Conclusion}

In conclusion, patients with NF1 have risk of PHEO/ PGL. The excess of catecholamines carries a significant morbidity and mortality risk if diagnosis is missed. Although these tumors are rare causes of hypertension after kidney transplantation, it is important to consider them especially in patients with predisposing genetic syndromes. A correct diagnosis is essential for definitive surgical management. Follow-up in our patient will include lifelong annual biochemical testing with 24-h urinary metanephrines for early detection of recurrent disease (3). This case highlights the safety, feasibility, early recovery and good outcome when performing a simultaneous bilateral adrenalectomy, as well as the importance of having a multidisciplinary approach that allows a successful treatment of this challenging disease.

\section{Declaration of interest}

The authors declare that there is no conflict of interest that could be perceived as prejudicing the impartiality of the research reported.

\section{Funding}

This research did not receive any specific grant from any funding agency in the public, commercial or not-for-profit sector.

\section{Patient consent}

Written, informed consent has been obtained from the patient for the publication of this article.

\section{Author contribution statement}

Valeria de Miguel and Andrea Paissan: Endocrinologists of the patient. Patricio García Marchiñena and Alberto Jurado: Urologist-of the patient (Surgical team). José Alfie: Clinician of the patient. Mariana Isola: Pathologist. Patricia Fainstein Day: Endocrinologist (Chief) Collaborate with the discussion.

\section{References}

1 Radtke HB, Sebold CD, Allison C, Haidle JL \& Schneider G. Neurofibromatosis type 1 in genetic counseling practice: recommendations of the National Society of Genetic Counselors. Journal of Genetic Counseling 200716 387-407. (https://doi. org/10.1007/s10897-007-9101-8)

2 Lenders JWM, Duh QY, Eisenhofer G, Gimenez-Roqueplo AP, Grebe SKG, Murad MH, Naruse M, Pacak K, Young WF Jr \& Endocrine Society. Pheochromocytoma and paraganglioma: an endocrine society clinical practice guideline. Journal of Clinical Endocrinology and Metabolism 201499 1915-1942. (https://doi. org/10.1210/jc.2014-1498)

3 Gruber LM, Erickson D, Babovic-Vuksanovic D, Thompson GB, Young WF Jr \& Bancos I. Pheochromocytoma and paraganglioma in patients with neurofibromatosis type 1. Clinical Endocrinology 2017 86 141-149. (https://doi.org/10.1111/cen.13163)

4 Yanik EL, Smith JM, Shiels MS, Clarke CA, Lynch CF, Kahn AR, Koch L, Pawlish KS \& Engels EA. Cancer risk after pediatric solid organ transplantation. Pediatrics 2017139 e20163893. (https://doi. org/10.1542/peds.2016-3893)

5 Lazareth H, Cohen D, Vasiliu V, Tinel C, Martinez F, Grünfeld JP, Mamzer MF, Legendre C \& Sberro-Soussan R. Paraganglioma of the bladder in a kidney transplant recipient: a case report. Molecular and Clinical Oncology 20176 553-555. (https://doi.org/10.3892/ mco.2017.1182)

6 Hope DCD \& Palan JM. Unusual presentation of phaeochromocytoma. BMJ Case Reports 20162016 bcr2016214719. (https://doi.org/10.1136/bcr-2016-214719)

7 Suzuki H, Abe M, Tahira K, Ito M, Takashima H, Baba S, Okada K \& Soma M. Successful treatment of pheochromocytoma in a patient with hemodialysis: a case report and review of the literature. Renal Failure 201335 1429-1433. (https://doi.org/10.3109/0886022X.2013.828307)

8 Hanna-Moussa A, Kurukulasuriya LR \& Sowers JR. Malignant pheochromocytoma presenting with uncontrolled hypertension after kidney transplant. Journal of Clinical Hypertension 201012 105-108. (https://doi.org/10.1111/j.1751-7176.2009.00221.x)

9 Montenovo MI, Jalikis FG, Hoch B \& Bakthavatsalam R. A symptomatic de novo pheochromocytoma 23 years after liver transplantation: a case report and review of the literature. Case Reports in Transplantation 20142014 934385. (https://doi. org/10.1155/2014/934385)

10 Yadav K, Bakshi G, Prakash G, Tamhankar A \& Verma K. Simultaneous bilateral laparoscopic adrenalectomy for pheochromocytoma in multiple endocrine neoplasia (MEN) syndrome: case report with review literature. International Journal of Surgery Case Reports 20145 487-490. (https://doi.org/10.1016/j. ijscr.2014.03.007)

Received in final form 21 February 2019

Accepted 8 April 2019 